\title{
The role of dispositional and social factors in Argentinian and Spanish women's sexuality
}

\section{Ruiz-Palomino Estefanía, Cristina Giménez-García, M. Dolores Gil Llario, Rafael Ballester Arnal \& Casteñeiras Claudia}

To cite this article: Ruiz-Palomino Estefanía, Cristina Giménez-García, M. Dolores Gil Llario, Rafael Ballester Arnal \& Casteñeiras Claudia (2019): The role of dispositional and social factors in Argentinian and Spanish women's sexuality, Journal of Sex \& Marital Therapy, DOI: 10.1080/0092623X.2019.1610122

To link to this article: https://doi.org/10.1080/0092623X.2019.1610122

Accepted author version posted online: 21 Apr 2019.

Submit your article to this journal $₫$

View Crossmark data $\nearrow$ 
Running head: Psychosocial factors in Argentinian and Spanish women.

The role of dispositional and social factors in Argentinian and Spanish women's sexuality. Ruiz-Palomino Estefanía a, Cristina Giménez-García ${ }^{a}$, M. Dolores Gil Llario , Rafael Ballester Arnal $^{\mathrm{c}}$, Casteñeiras Claudia ${ }^{\mathrm{d}}$

a Jaume I University, Department of Clinical and Basic Psychology and Psychobiology, Castellon, Spain

${ }^{\mathrm{b}}$ University of Valencia. General Study, Developmental and Education Psychology, Valencia, Spain

${ }^{\mathrm{c}}$ Jaume I University, Basic and Clinic Psycology and Psycobiology, Avda. Sos Baynat S/n, CASTELLÓN, 12004 Spain

${ }^{\mathrm{d}}$ Universidad Nacional de Mar del Plata, Mar del Plata, 7600 Argentina

Corresponding author Cristina Giménez-García gimenezc@uji.es

\section{Abstract}

This study examines the role of sociocultural and dispositional factors in the sexual expressions of young Argentinian and Spanish women. Three hundred young women selfevaluated their sexual practices, sexual orientation and relationships. Results reveal differences in women's sexuality based on societal and dispositional variables. The latter seem to play a more important role in those sexual behaviors that are normative in Hispanic traditions, while gender dissimilarity is more relevant when these behaviors are socially censured. Therefore, women's sexuality in Hispanic traditions, such as in Argentina and Spain, seems to be more complex than past studies reported.

Keywords: women; sexuality; gender dissimilarities; sexual sensation seeking; sexual compulsivity. 


\section{Introduction}

A comprehensive sexuality is an important dimension for women's wellbeing (Flynn, \& Gow, 2015). However, traditions such as the Hispanic culture, based on gender values such as marianismo (i.e., women characterized by honorability and being submissive to men) and machismo (i.e., men characterized by strength, autonomy and authoritarianism) have made this difficult to achieve (Ballester, Gil, Giménez, \& Edo, 2010; Espinosa-Hernández, Vasilenko, McPherson, Gutierrez, \& Rodriguez, 2017; Lamb, 2010). Some cross-cultural studies about sexuality have revealed important differences between the Hispanic tradition and other cultures from northern countries. For example, young Euro-American women have reported more self-confidence than their Costa Rican counterparts, in particular, in sexual experience (Rodríguez-Arauza, Mealy, Smith, \& DíPlacido, 2013). Regarding gendered scripts and violence, young Latin American women have reported more acceptance of sexual harassment than young North American women (DeSouza, Pryor, Ribeiro, Mello, \& Camino, 2004). Concerning sexual orientation (Steffens, Jonas, \& Denger, 2015), Mexicans have exhibited less open-minded attitudes toward sexual diversity than those reported by young German people. In particular, the first revealed more negative attitudes toward lesbian women than the second.

In any case, dissimilarities have also been observed among Hispanic women. In particular, expressions of sexual orientation seem to be diverse among young Hispanic women (Deardorff, Tschann, \& Flores, 2008). For example, one study focused on young Mexicans and Spaniards (Gil-Llario, Morell-Mengual, Ballester-Arnal, Giménez-García, \& CastroCalvo, 2016) revealed differences in non-heterosexual self-identification $(0.4 \%$ and $15 \%$ respectively). Another study in which young Bolivian, Chilean and Spanish people participated (Ilabaca, Fuertes, \& Orgaz, 2015) suggested differences in these groups 
regarding sexual attitudes and sexual self-esteem, these being more positive for young Spaniards than for Bolivian and Chilean youngsters. Moreover, regarding sexual health, dissimilarities were also found between Spanish and Mexican women (Giménez-García, Ballester-Arnal, Gil-Llario, Cárdenas-López, \& Duran-Baca, 2012), the former reporting a greater number of safe sexual behaviors than the latter.

In light of these differences, several authors have attempted to explain what underlies women's sexuality. For example, social constructionist theories predict that sexual differences mainly depend on socialization and culture (DeLamater, \& Hyde, 1998). In this sense, these may be related to gender dissimilarity (Schmitt, \& the International Sexuality Description Project, 2004). In accordance with this line of thinking, past studies in Hispanic cultures such as Spain and Mexico (Gil-Llario, Giménez-García, Ballester-Arnal, CárdenasLópez, \& Durán-Baca, 2016) have reported differences, based on the Gender Inequality Index (United Nations Development Programme, 2015), in aspects such as frequency of sexual practices or sexual orientation.

Nevertheless, personal characteristics may also mediate the social relevance of women's sexuality (Reese-Weber, \& McBride, 2015). In this regard, recent research has suggested that dispositional variables may influence women's sexuality, these ranging from heritability variables (Alanko et al., 2010) to individual factors such as impulsivity (Dosch, Rochat, Ghisletta, Favez, \& Van der Linden, 2016) or sexual sensation seeking. In fact, a predisposition to seek sexually exciting experiences has been found to have an important weight in sexual activities such as masturbation or petting (Walton, Lykins, \& Bhullar, 2016), as well as sexual frequency, diversity of sexual activities or risk-taking in sexual behaviors (Norris et al., 2009). Therefore, sexual arousal may determine sexual behaviors in spite of personal beliefs and values (Ariely, \& Loewenstein, 2006). 
In all probability, sociocultural values moderate sexuality, and biological motivations and personal experiences also play an important role (Baumeister, 2000). However, the weight of these variables on women's sexuality is still unknown (Apostolou, 2016). This is particularly true when this analysis focuses on the sexuality of women who have been socialized in sexually conservative traditions such as the Hispanic culture (Mann, 2016).

In order to explore this question, this study analyzes Argentinian and Spanish women's sexuality through three dimensions (type of activity, orientation, and relationship) in order to evaluate the possible influence of (1) sociocultural factors assessed by the gender inequality index, and (2) dispositional traits assessed by sexual sensation seeking and sexual compulsivity.

\section{Materials and method}

\section{Participants}

This study involved 300 young women from Argentina (45\% of participants) and Spain (55\% of participants). Participants were college students and their ages ranged between 18 and 26 years old: the average age of the Argentinian women was 21.88 years $(\mathrm{SD}=2.34)$ and that of the Spanish women was 21.20 years $(\mathrm{SD}=1.91)$, with statistically significant differences $(\mathrm{t}=-2.75 ; \mathrm{p} \leq .006)$. All of them were middle-class individuals living in cities. In this sense, there were no statistically significant differences.

\section{Instruments}

The Sexual Scale of the AIDS Prevention Questionnaire (Ballester, Gil, \& Giménez, 2007) evaluates sexual experience through yes/no questions. In particular, it explores the type of sexual practices and sexual orientation, same-sex behavior, being in a relationship, and being unfaithful. This Questionnaire, aimed at young people, contextualizes sexual experience in the recent situation of HIV-AIDS through 65 items based on socio-cognitive 
models. The AIDS Prevention Questionnaire yielded a Cronbach's alpha value of .70 and a correlation value of 0.830 by test-retest reliability (Ballester et al., 2007). In particular, this Sexual Scale obtained a Cronbach's alpha value of .60 for Spanish women and a value of .64 for Argentinian women.

The Spanish version of the Sexual Sensation Seeking Scale (Kalichman \& Rompa, 1995) by Ballester et al. (2008). This instrument evaluates the predisposition to seek new or risky sexual stimulation by means of an 11-item scale ranging from 1 (uncharacteristic of me) to 4 (very characteristic of me). The internal consistency of the Spanish adaptation was .70 (Ballester et al., 2008). In this study, the Scale obtained a Cronbach's alpha of .82 for Argentinian women and .78 for Spanish women.

The Spanish version of the Sexual Compulsivity Scale (Kalichman \& Rompa, 1995) by Ballester et al. (2013). This instrument evaluates the predisposition to experience sexual concern and hypersexuality on a 10-item scale ranging from 1 (uncharacteristic of me) to 4 (very characteristic of me). The Spanish version obtained an Alpha coefficient of .83 and a correlation value of .72 for test-retest reliability (Ballester et al., 2013). In this study, the Scale obtained a Cronbach's alpha coefficient of .77 for Argentinian women and .80 for Spanish women.

To adapt these instruments for Argentinian participants, firstly, two experienced professionals and two researchers examined the instrument. They examined the vocabulary, the content and the format of the instrument through inter-rater agreement. Afterwards, the young Argentinian women answered the scales so that their psychometric characteristics could be analyzed. 


\section{Ethics Statement}

The study and procedures were approved by the Ethics Committees of the respective participating centers, in Mar del Plata (Argentina) and Castellón (Spain). This study complied with the ethical standards of the institutional research committee and the Declaration of Helsinki.

\section{Procedure}

In order to recruit participants, information about the study was disseminated in similar outreach activities about health promotion carried out in their colleges. Once participants had agreed to take part and had given their informed consent, they self-administered the questionnaires in rooms set aside for this purpose at the universities, which took 30-40 minutes. A trained psychologist explained the instructions and supported participants in each country. Their participation was voluntary, confidential and anonymous.

\section{Analyses}

To examine differences in women's sexuality due to sociocultural and dispositional variables, we used differential analyses $\left(\mathrm{Chi}^{2}\right.$ test $)$. The magnitude of these differences was estimated by Cramer's phi. Secondly, in order to determine the most effective predictors of women's sexuality, we performed the regression analysis, controlling for the possible influence of age on these results. The sociocultural variable was assessed by the Gender Inequality Index (GII), in which Spain shows a more balanced position (score of 0.09 , ranking $16^{\text {th }}$ out of 155 ) than Argentina (score of 0.37 , ranking $75^{\text {th }}$ out of 155 ). Because the social conditions are similar in the two groups, in Spain and Argentina, the influence of gender inequality could be expected to be similar. Dispositional variables were assessed by sexual sensation seeking (SSS) and sexual compulsivity (SC) scores. In order to facilitate data processing, we divided participants into two groups based on a cut-off point at the $80^{\text {th }}$ 
percentile, as defined in previous studies (Castro-Calvo, 2017). The cut-off point for the Sexual Sensation Scale was 29 and for the Sexual Compulsivity Scale it was 14. Consequently, participants were divided into two groups (low score group and high score group).

\section{Results}

Regarding the sexual experience of Argentinian and Spanish women, the participants in our study have revealed significant statistical differences for most of the sexual variables evaluated (see Table 1). Regarding sexual activities, Spanish women exceeded Argentinian women in all practices except for anal sex, which did not reveal any significant statistical differences. The most important differences were related to masturbation and mutual masturbation. Moreover, Spanish women exceeded Argentinian women in reporting samesex behavior and self-identifying as bisexual, while Argentinian women exceeded Spanish women in self-identifying as heterosexual. In any case, for both groups, the number of same-sex practices was higher than self-identification as homosexual or bisexual. Regarding relational variables, both groups revealed similar scores.

Concerning dispositional variables, the women's sexuality showed differences based on sexual sensation seeking and sexual compulsivity scores (see Table 2). Women belonging to the higher score group revealed more prevalence for all sexual practices, although these differences were statistically significant for masturbation, oral and anal sex depending on SSS, SC or both. Regarding sexual orientation, the women in the higher score group of SC reported more non-heterosexist self-identification. Moreover, the higher score groups of SC and SSS revealed more frequent same-sex practices and unfaithfulness than women who belonged to the lower score groups. Therefore, some dissimilarities based on SSS and SC were different from those based on origin (Argentina or Spain). 
In relation to possible predictors for these sexual dimensions, the regression analyses (see Table 3) showed how all these sexual practices were modulated by dispositional variables except for vaginal sex, which was influenced by age. In particular, mutual masturbation and oral sex were only associated with sexual sensation seeking (explaining $35 \%$ and $28 \%$ of variances respectively) and anal sex was also related to sexual compulsivity and being Argentinian or Spanish (explaining 19\% of variance). Additionally, being Argentinian or Spanish together with sexual sensation seeking explained $33 \%$ of the variance for masturbation. Regarding sexual orientation, sexual compulsivity was the only variable that explained the percentages in self-informed as heterosexual and self-informed as bisexual, as well as same-sex behavior, accounting for between $25 \%$ and $17 \%$ of variance. Finally, being unfaithful was only related to sexual sensation seeking, which explained $12 \%$ of variance. We carried out interaction effects for all these analyses but they were not statistically significant.

\section{Discussion}

This study reveals the complexity of sexuality in young women from two Hispanic countries (Argentina and Spain). In particular, our findings suggest that some specific sexual dimensions (sexual practices, sexual orientation and relationships) would be influenced differently by dispositional and social variables.

Regarding sexual practices, these women reveal differences based on both sociocultural and dispositional variables. However, the latter play a more important role in these sexual behaviors, while a gendered sociocultural environment would only modulate masturbation and anal sex. As other researchers have described (Walton et al., 2016), variables such as sexual sensation seeking or sexual compulsivity may be relevant for women's sexual experience. In any case, there is also an influence of gendered sociocultural environment on 
specific behaviors, in line with past results (Schmitt, \& the International Sexuality Description Project, 2004; Singh, Wulf, Samara, \& Cuca, 2000).

In addition, there would be a difference between sexual behaviors that are normative in gendered sexual scripts and sexual behaviors that are stigmatized. In particular, this difference would be more relevant when these sexual behaviors involve social interaction, such as anal sex. According to our results, the weight of a gendered sociocultural environment is higher for anal sex, while the weight of dispositional variables is higher for masturbation, an isolated sexual behavior. Additionally, the more normative practice (vaginal sex) is only related to age. In line with other authors (Gil-Llario et al., 2016), women would be more likely to develop their sexuality throughout their life cycle in those practices that are common in gendered societies, while a gendered sociocultural environment would make censured behaviors more unlikely.

Regarding sexual orientation, the main differences are based on dispositional variables, although a gendered sociocultural environment also shows some dissimilarities. In accordance with previous studies (Ortiz-Hernández, 2004), women who were socialized in a more equal environment (in this study, Spanish women) would report more nonheterosexual experiences than those who were socialized in a more unequal environment (Argentinian women). That is, those environments that maintain more gendered scripts would promote additional difficulties to guarantee expressions of sexual diversity. In any case, as past results have found (Gil-Llario et al., 2016), our findings reveal that expressions of sexual orientation are mainly influenced by dispositional variables rather than by a gendered sociocultural environment. In particular, sexual compulsivity would modulate the reporting of bisexuality and same-sex practices for these Argentinian and Spanish women. 
As regards relationships, only dispositional variables have shown any differences. In particular, sexual sensation seeking seems to modulate their occurrence, as reflected in the number of sexual partners (Norris et al., 2009).

Limitations

These findings should be evaluated bearing in mind a number of limitations. In this study, these include social desirability, as well as the use of self-reported questionnaires. In any case, the validation of the questionnaires took this aspect into account.

Concluding remarks

Our findings have revealed important new knowledge regarding the sexuality of young Argentinian and Spanish women. That is, dispositional variables such as sexual sensation seeking and sexual compulsivity would play an important role in the expressions of women's sexuality. In addition, being socialized in gendered societies would be more relevant for those practices that are more stigmatized in gendered cultures. Therefore, in order to promote sexual health and wellbeing among these young women, practitioners and policies should incorporate both types of variables in their sexual policies and programs, taking into account the differential weights of their influence.

\section{References}

Alanko, K., Santtila, P., Harlaar, N., Witting, K., Varjonen, M., Jern, P., Johansson, A., von der Pahlen, B., \& Sandnabba, N.K. (2010). Common genetic effects of gender atypical behaviour in childhood and sexual orientation in adulthood: a study of Finnish twins. Archives of sexual behavior, 39(1), 81-92.

Apostolou, M. (2016). The Evolution of Female Same-Sex Attractions: The Weak Selection Pressures Hypothesis. Evolutionary Behavioural Sciences, 10(4), 270283. 
Ariely, D., \& Loewenstein, G. (2006). The heat of the moment. The effect of sexual arousal on sexual decision-making. Journal of Behavioral Decision Making, 19(2), 87-98.

Ballester, R., Gil, M.D., Giménez, C., \& Edo, M. (2010). Desarrollo del constructo de masculinidad/feminidad en la adolescencia/Development of the construct of masculinity/femininity in adolescence. In L. Abad and J.A. Flores (eds.) Emociones y sentimientos: la construcción social del amor (pp. 265-278). Cuenca: Universidad de Castilla-La Mancha.

Ballester, R., Gil, M.D., Ruiz, E., Giménez, C., \& Gómez., S. (2008). El cuestionario de búsqueda de sensaciones sexuales: adaptación y validación en una muestra española/Sexual sensation seeking scale: adaptation and validation in Spanish population. Poster presented at VI Congreso Nacional de la Asociación Española de Psicología Clínica y Psicopatología. Huelva, Spain.

Ballester, R., Gómez, S., Gil, M.D., \& Salmerón, P. (2013). Sexual compulsivity scale (SCS): Adaptation and validation in Spanish population. Journal of Sex \& Marital Therapy, 6(39), 526-540.

Baumeister, R.F. (2000). Gender Differences in Erotic Plasticity: The Female Sex Drive as Socially Flexible and Responsive. Psychological Bulletin, 126(3), 347-374.

Boone, T. L. (2015). Messages about sexuality: An ecological perspective. Sex Education, $15(4), 437-450$.

Burri, A. (2017). Sexual Sensation Seeking, Sexual Compulsivity, and Gender Identity and Its Relationship With Sexual Functioning in a Population Sample of Men and Women. The Journal of Sexual Medicine, 14(1), 69-77. 
Castro-Calvo, J. (2017). Prevalencia, comorbilidad y correlatos psicológicos de la compulsividad sexual/Prevalence, comorbidity, and psychological correlates of sexual compulsivity (PhD dissertation). Universitat Jaume I, Castellón, Spain.

Deardorff, J., Tschann, J.M., \& Flores, E. (2008). Sexual values among Latino youth: Measurement development using a culturally based approach. Cultural Diversity and Ethnic Minority Psychology, 14(2), 138-146.

DeLamater, J. D., \& Hyde, J.S. (1998). "Essentialism vs. social constrûctionism in the study of human sexuality". The Journal of Sex Research, 35(1), 10-18.

DeSouza, E.R., Pryor, J.B., Ribeiro, J., Mello, J., \& Camino, C. (2004). Female nurses' and educators' reactions to sexual harassment charges: a cross-cultural perspective. Interamerican Journal of Psychology, 38(1), 33-40.

Dosch, A., Rochat, L., Ghisletta, P., Favez, N., \& Van der Linden, M. (2016). Psychological Factors Involved in Sexual Desire, Sexual Activity, and Sexual Satisfaction: A Multi-factorial Perspective. Archives of Sexual Behavior, 45(8), 2029-2045.

Espinosa-Hernández, G., Vasilenko, S.A., McPherson, J.L., Gutierrez, E., \& Rodriguez, A. (2017). Brief report: The role of three dimensions of sexual well-being in adolescents' life satisfaction. Journal of Adolescence, 55, 61-65.

Flynn, T.J., \& Gow., A.J. (2015). Examining associations between sexual behaviours and quality of life in older adults. Age and ageing, 44 (5), 823-828.

Gil-Llario, M.D., Giménez-García, C., Ballester-Arnal, R., Cárdenas-López, G., \& DuránBaca, X. (2016). Gender, sexuality and relationships in young Hispanic people. Journal of Sex and Marital Therapy, 43(5), 456-462. 
Gil-Llario, M.D., Morell-Mengual, V., Ballester-Arnal, R., Giménez-García, C., \& CastroCalvo, J. (2016). Sexual sensation seeking in Spanish young men and women with different sexual orientations. Journal of Sexual and Marital Therapy, 41(5), 525530.

Gil-Llario, M.D., Ruiz-Palomino, E., Morell-Mengual, V., Giménez-García, C., \& Ballester-Arnal, R. (2018). Validation of the AIDS Prevention Questionnaire: A Brief Self-Report Instrument to Assess Risk of HIV Infection and Guide Behavioral Change. AIDS and Behavior. https://doi.org/10.1007/s10461-018-2224-0

Giménez-García, C., Ballester-Arnal, R., Gil-Llario, M.D., Cárdenas-López, G., \& DuránBaca, X. (2013). Culture as an Influence on the Perceived Risk of HIV Infection: A Differential Analysis Comparing Young People from Mexico and Spain. Journal of Community Health, 38(3), 434-42.

Giménez-García, C.; Ruiz-Palomino, E.; Gil-Llario, M.D., Ballester-Arnal, R. \& Castañeiras, C. (2018). Why Do Young Hispanic Women Take Sexual Risks? Psychological and Cultural Factors for HIV Prevention. Journal of the association of nurses in aids care, 29(5), 762-769.

Hungrige, A. (2017). Women's masturbation: An exploration of the influence of shame, guilt, and religiosity. Dissertation Abstracts International: Section B: The Sciences and Engineering, 78(3-B(E)).

Ilabaca, P., Fuertes, A., \& Orgaz, B. (2015). Impacto de la Coerción Sexual en la Salud Mental y Actitud Hacia la Sexualidad: Un Estudio Comparativo Entre Bolivia, Chile y España/Impact of sexual coercion on mental health and attitude toward sexuality: A comparative study between Bolivia, Chile, and Spain. Psykhe: Revista de la Escuela de Psicología, 24(1), 1-13. 
Kalichman, S.C., \& Rompa, D. (1995). Sexual sensation seeking and sexual compulsivity scales: Reliability, validity, and predicting HIV risk behavior. Journal of Personality Assessment, 65(3), 586-601.

Lalasz, C.B., Weigel, D.J. (2011). Understanding the relationship between gender and extradyadic relations: The mediating role of sensation seeking on intentions to engage in sexual infidelity. Personality and Individual Differences, 50 (7), 10791083.

Lamb, S. (2010). Feminist Ideals for a Healthy Female Adolescent Sexuality: A Critique. Sex Roles, 62 (5), 294-306.

Mann, E. (2016). Latina Girls, Sexual Agency, and the Contradictions of Neoliberalism. Sexuality Research and Social Policy, 13(4), 330-340.

McBride, K. R., Sanders, S. A., Hill, B. J., \& Reinisch, J. M. (2017). Heterosexual women's and men's labeling of analbehaviors as having "had sex". Journal of Sex Research, 54(9), 1166-1170.

Ortiz-Hernández, L. (2004). La opresión de minorías sexuales desde la inequidad de género/The opression of sexual minorities through gender inequity. Política $y$ Cultura, 22, $161-182$.

Reese-Weber, M., \& McBride, D.M. (2015). The effects of sexually-explicit literature on sexual behaviours and desires of women. Psychology of Popular Media Culture, 4(3), 251- 257.

Rodríguez-Arauza, G., Mealy, M., Smith, V., \& DiPlacido, J. (2013). Sexual behavior in Costa Rica and the United States. International Journal of Intercultural Relations, 37(1), 48-57. 
Santos-Iglesias, P., Castro, A., Barbosa, M., \& Nobre, P.J. (2017) Sexual Functioning in Spanish and Portuguese Young Adults: Initial Validation of the Arizona Sexual Experience Scale. International Journal of Sexual Health, 29(2), 155-167.

Schmitt, D. P., \& the International Sexuality Description Project. (2004). Patterns and universals of adult romantic attachment across 62 cultural regions: Are models of self and of other pancultural constructs?. Journal of Cross-Cultural Psychology, 35(4), 367-402.

Singh, S., Wulf, D., Samara, R., \& Cuca, Y. (2000). Gender Differences in the Timing of First Intercourse: Data from 14 Countries. International Family Planning Perspectives, 26(1), 21-43.

Steffens, M. C., Jonas, K. J., \& Denger, L. (2015). Male role endorsement explains negative attitudes toward lesbians and gay men among students in Mexico more than in Germany. Journal of Sex Research, 52(8), 898-911.

United Nations Development Programme. (2015). 2015 Human Development Report. Accessed December 8, 2016 http://hdr.undp.org/en/2015-report/download

Urrea, F. \& Poso, J. (2015). Feminidades, sexualidades y colores de piel: Mujeres negras, indigenas, blancas-mestizas y transgeneristas negras en el suroccidente colombiano/ Feminities, sexualities and skin colors: Afroamerican, indigenous, mestizo and Afroamerican transgender women in southwestern Colombia. Colombia: Universidad del Valle.

Walton, M., Lykins, A., \& Bhullar, N. (2016). Sexual Arousal and Sexual Activity Frequency: Implications for Understanding Hypersexuality Archives of Sexual Behavior, 45(4), 777-782. 
Worsley, R., Santoro, N., Miller, K.K., Parish, S.J., Davis, S.R. (2016). Hormones and Female Sexual Dysfunction: Beyond Estrogens and Androgens--Findings from the Fourth International Consultation on Sexual Medicine. The journal of sexual medicine, 13(3), 283-290.

Table 1. Differential analyses of women's sexuality based on societies with dissimilar GII.

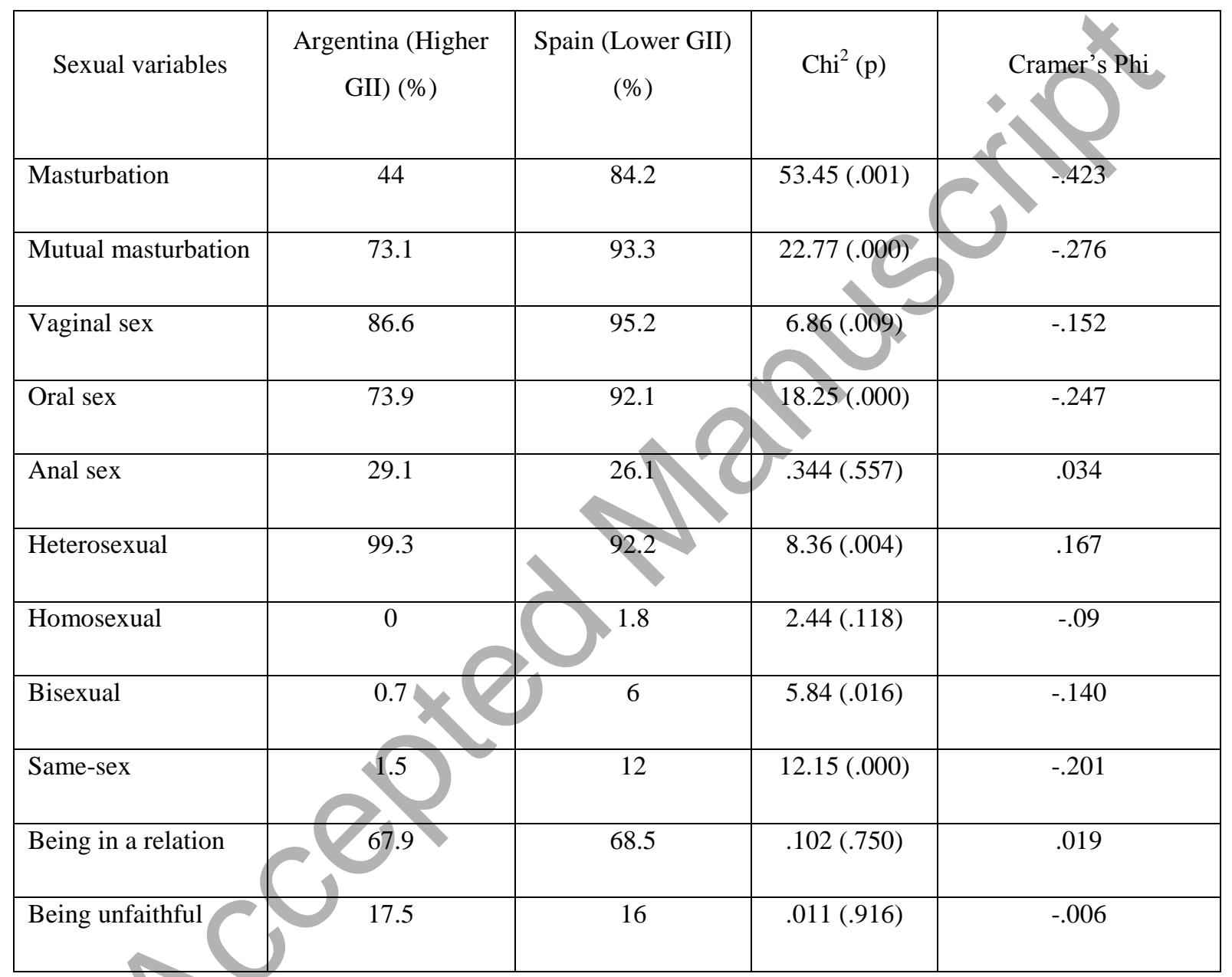

Table 2. Differential analyses of women's sexuality based on level of dispositional variables.

\begin{tabular}{|c|c|c|c|c|c|c|c|c|}
\hline 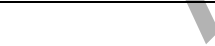 & \multicolumn{4}{|c|}{ Sexual Sensation Seeking } & \multicolumn{4}{|c|}{ Sexual compulsivity } \\
\hline $\begin{array}{l}\text { Sexual } \\
\text { variables }\end{array}$ & $\begin{array}{c}\text { Low score } \\
\%\end{array}$ & $\begin{array}{c}\text { High score } \\
\%\end{array}$ & $\begin{array}{l}\mathrm{Chi}^{2} \\
\text { (p) }\end{array}$ & $\begin{array}{c}\text { Cramer's } \\
\text { Phi }\end{array}$ & $\begin{array}{c}\text { Low score } \\
\%\end{array}$ & $\begin{array}{c}\text { High score } \\
\%\end{array}$ & $\begin{array}{r}\mathrm{Chi}^{2} \\
\text { (p) }\end{array}$ & $\begin{array}{c}\text { Cramer's } \\
\text { Phi }\end{array}$ \\
\hline Masturbation & 69 & 94.7 & $\begin{array}{l}10.159 \\
(.001)\end{array}$ & .213 & 69 & 92.2 & $\begin{array}{l}8.954 \\
(.003)\end{array}$ & .194 \\
\hline
\end{tabular}




\begin{tabular}{|c|c|c|c|c|c|c|c|c|}
\hline $\begin{array}{l}\text { Mutual } \\
\text { masturbation }\end{array}$ & 85.5 & 94.7 & $\begin{array}{l}2.405 \\
(.121)\end{array}$ & .101 & 87 & 87.2 & $\begin{array}{c}.001 \\
(.976)\end{array}$ & .002 \\
\hline Vaginal sex & 92.5 & 97.4 & $\begin{array}{l}1.207 \\
(.272)\end{array}$ & .071 & 93 & 94.9 & $\begin{array}{c}.183 \\
(.669)\end{array}$ & .028 \\
\hline Oral sex & 85 & 100 & $\begin{array}{l}6.522 \\
(.011)\end{array}$ & .166 & 86 & 94.9 & $\begin{array}{l}2.340 \\
(.126)\end{array}$ & .099 \\
\hline Anal sex & 25 & 47.4 & $\begin{array}{l}7.829 \\
(.005)\end{array}$ & .181 & 24.5 & 48.7 & $\begin{array}{l}9.403 \\
(.002)\end{array}$ & .198 \\
\hline Heterosexual & 95 & 92 & $\begin{array}{c}.530 \\
(.467)\end{array}$ & .-047 & 96.5 & & $\begin{array}{l}9.031 \\
(.003)\end{array}$ & -.194 \\
\hline Homosexual & 1 & 2.6 & $\begin{array}{c}.691 \\
(.406)\end{array}$ & .054 & & & $\begin{array}{l}5.674 \\
(.017)\end{array}$ & .154 \\
\hline Bisexual & 4 & 5.3 & $\begin{array}{c}.131 \\
(.717)\end{array}$ & & & 10.3 & $\begin{array}{l}4.325 \\
(.038)\end{array}$ & .134 \\
\hline Same-sex & 5.5 & 26.3 & $\begin{array}{l}17.32 \\
(.000)\end{array}$ & & 4.5 & 30.8 & $\begin{array}{l}28.27 \\
(.000)\end{array}$ & .343 \\
\hline $\begin{array}{l}\text { Being in a } \\
\text { relation }\end{array}$ & 67 & 6 & & .011 & 67.7 & 63.2 & $\begin{array}{c}.293 \\
(.588)\end{array}$ & -.035 \\
\hline $\begin{array}{l}\text { Being } \\
\text { unfaithful }\end{array}$ & 11.9 & & $\begin{array}{l}9.547 \\
(.002)\end{array}$ & 203 & 11.9 & 31.6 & $\begin{array}{l}9.649 \\
(.002)\end{array}$ & .204 \\
\hline
\end{tabular}

Table 3. Logistic regression analysis of women's sexuality.

\begin{tabular}{|c|c|c|c|c|c|c|c|c|c|}
\hline Variable & & ds Ratio & $\mathrm{p}$ & $\begin{array}{r}\text { In } \\
\text { Con } \\
\text { Low }\end{array}$ & $\begin{array}{l}\text { val } \\
\text { ence } \\
\text { Upper }\end{array}$ & $\overline{\mathrm{R}^{2}}$ & Chi & $\mathrm{df}$ & $\mathrm{p}$ \\
\hline \multirow{4}{*}{ Masturbation } & GII & .304 & .004 & .134 & .689 & \multirow{4}{*}{.328} & \multirow{4}{*}{60.484} & \multirow{4}{*}{4} & \multirow{4}{*}{.000} \\
\hline & Age & 1.176 & .083 & .979 & 1.413 & & & & \\
\hline & SSS & 1.154 & .001 & 1.064 & 1.251 & & & & \\
\hline & $\mathrm{SC}$ & 1.051 & .539 & 1.051 & 1.234 & & & & \\
\hline \multirow{4}{*}{$\begin{array}{c}\text { Mutual } \\
\text { masturbation }\end{array}$} & GII & .351 & .061 & .118 & 1.048 & \multirow{4}{*}{.280} & \multirow{4}{*}{38.949} & \multirow{4}{*}{4} & \multirow{4}{*}{.000} \\
\hline & Age & 1.269 & .058 & .992 & 1.622 & & & & \\
\hline & SSS & 1.219 & .001 & 1.082 & 1.372 & & & & \\
\hline & $\mathrm{SC}$ & .873 & .120 & .736 & 1.036 & & & & \\
\hline \multirow{2}{*}{ Vaginal sex } & GII & .369 & .183 & .085 & 1.601 & \multirow{2}{*}{.199} & \multirow{2}{*}{19.231} & \multirow{2}{*}{4} & \multirow{2}{*}{.001} \\
\hline & Age & 1.560 & .015 & 1.092 & 2.228 & & & & \\
\hline
\end{tabular}




\begin{tabular}{|c|c|c|c|c|c|c|c|c|c|}
\hline & SSS & 1.138 & .079 & .985 & 1.315 & & & & \\
\hline & $\mathrm{SC}$ & .918 & .428 & .742 & 1.135 & & & & \\
\hline \multirow{4}{*}{ Oral sex } & GII & 1.259 & .685 & .414 & 3.831 & \multirow{4}{*}{.349} & \multirow{4}{*}{48.766} & \multirow{4}{*}{4} & \multirow{4}{*}{.000} \\
\hline & Age & 1.194 & .156 & .935 & 1.524 & & & & \\
\hline & SSS & 1.391 & .000 & 1.200 & 1.612 & & & & \\
\hline & $\mathrm{SC}$ & .899 & .336 & .723 & 1.117 & & & & \\
\hline \multirow{4}{*}{ Anal sex } & GII & 2.567 & .024 & 1.130 & 5.832 & \multirow{4}{*}{.191} & \multirow{4}{*}{33.994} & \multirow{4}{*}{4} & \multirow{4}{*}{.000} \\
\hline & Age & 1.252 & .006 & 1.065 & 1.472 & & & & \\
\hline & SSS & 1.089 & .012 & 1.019 & 1.164 & & & & \\
\hline & SC & 1.153 & .007 & 1.040 & 1.278 & & & & \\
\hline \multirow{4}{*}{ Heterosexual } & GII & 115975931.7 & .997 & .000 & - & \multirow{4}{*}{.210} & \multirow{4}{*}{17.937} & \multirow{4}{*}{4} & \multirow{4}{*}{.001} \\
\hline & Age & .858 & .344 & .624 & 1.179 & & & & \\
\hline & SSS & 1.014 & .831 & .891 & 1.155 & & & & \\
\hline & $\mathrm{SC}$ & .823 & .008 & .712 & .951 & & & & \\
\hline \multirow{4}{*}{ Homosexual } & GII & . 000 & .997 & .000 & - & \multirow{4}{*}{.193} & & \multirow{4}{*}{4} & \multirow{4}{*}{.207} \\
\hline & Age & 1.419 & .290 & .742 & 2.712 & & & & \\
\hline & SSS & .953 & .728 & .728 & 1.248 & & & & \\
\hline & $\mathrm{SC}$ & 1.278 & .073 & .977 & 1.673 & & & & \\
\hline \multirow{4}{*}{ Bisexual } & GII & .000 & .997 & .000 & - & \multirow{4}{*}{.169} & \multirow{4}{*}{12.146} & \multirow{4}{*}{4} & \multirow{4}{*}{.016} \\
\hline & Age & 1.088 & .646 & .760 & 1.558 & & & & \\
\hline & SSS & .999 & .985 & .864 & 1.154 & & & & \\
\hline & $\mathrm{SC}$ & 1.174 & .046 & 1.003 & 1.375 & & & & \\
\hline \multirow{4}{*}{ Same-sex } & GII & .230 & .184 & .026 & 2.012 & \multirow{4}{*}{.250} & \multirow{4}{*}{28.74} & & \\
\hline & Age & 1.036 & .803 & .787 & 1.363 & & & 4 & 000 \\
\hline & SSS & 1.115 & .052 & .999 & 1.244 & & & 4 & .000 \\
\hline & $\mathrm{SC}$ & 1.183 & .007 & 1.048 & 1.337 & & & & \\
\hline & GII & .674 & .291 & .324 & 1.402 & & & & \\
\hline Being in a & Age & 1.158 & .058 & .995 & 1.347 & 032 & 5513 & 4 & 230 \\
\hline relation & SSS & 1.013 & .678 & .954 & 1.076 & (032 & 5.513 & 4 & .239 \\
\hline & SC & .964 & .458 & .874 & 1.063 & & & & \\
\hline & GII & 1.189 & .739 & .431 & 3.281 & & & & \\
\hline Being & Age & 1.187 & .095 & .971 & 1.451 & 122 & 16671 & 4 & 002 \\
\hline unfaithful & SSS & 1.089 & .036 & 1.005 & 1.180 & .122 & $10.0 / 1$ & 4 & .002 \\
\hline & $\mathrm{SC}$ & 1.105 & .077 & .989 & 1.235 & & & & \\
\hline
\end{tabular}

